Journal of Engineering and Fundamentals

Vol. 2(2), pp. 9-16, December , 2015

Available online at http://www.tjef.net

ISSN: 2149-0325

http://dx.doi.org/10.17530/jef.15.08.2.2

\title{
Bidirectional Intelligent Semiconductor Transformer
}

\author{
Loganathan Vijayaraja * \\ Assistant professor, Sri Sairam Institute Technology
}

Ravikumar Dhansekar
Assistant professor, Sri Sairam Institute Technology

* Correspondence: Sri Sairam Institute of Technology, Sai Leo Nagar, Chennai, Tamilnadu, India - 600044. Tel: +9884298051; E-mail address: vijaylogu_83@yahoo.com 


\section{Introduction}

Microgrid is the hottest research topic sine it solves energy demand issues we face in nowadays [1]-[4]. Conventional transformer can change only the magnitude of the ac voltage and the quality of supplying power is totally dependent on that of the input power. So, it cannot be applicable for the smart grid, in which the magnitude and frequency of the

operation voltage are various and high-quality power is required [5]-[6]. Intelligent semiconductor transformer or solid-state transformer was proposed by EPRI to replace the conventional transformer in railway systems and substations, in which light weight is mandatorily required. Recently, EPRI has reported $100 \mathrm{kVA}$ single-phase semiconductor transformers named intelligent universal transformer for distribution automation.

A distributed method for a PV and battery system is proposed. While the system is interfaced to the AC grid by the conventional rectifier and transformer, for a large power rating system, the system efficiency and transformer size might be a problem. In order to address the challenges discussed earlier, a typical DC microgrid system which is enabled by SST is presented in this method. The SST is used to interface the distributed AC system to low AC and DC microgrid, rather than a $60 \mathrm{~Hz}$ conventional transformer and rectifier [7]-[8].

\section{Solid state transformer topology}

SST is one of the newest family members of flexible ac transmission devices. The key idea for SST is to apply power electronics control technology and the state of art power device technology to increase the operating frequency of the transformer and therefore decrease its volume. The topology comprises three stages: AC/DC stage, DC/DC stage and DC/AC stage. The AC/DC stage rectifies the $60 \mathrm{~Hz}$ high voltage $\mathrm{AC}$ into a high
DC voltage. Then the middle DC/DC stage adopts dual active bridge topology to transform the high DC voltage to a regulated low DC voltage by using high frequency transformer. The low DC voltage can be used to enable the DC microgrid bus. Finally, the split-phase DC/AC inverter produces AC output voltage, which can be used to connect AC grid. Thus, the SST can be considered as a three-port energy router rather than a simple transformer.

\section{Converter for the pv, fuel cell and battery}

PV, fuel cell and battery modules share a common dc bus through power electronic interface, in which the DAB topology is adopted. DAB is controlled by simple phase shift modulation, so the bidirectional power flow is easy to be implemented. Furthermore, DAB achieves zero voltage switching in a wide operation range, guaranteeing the high efficiency.

\section{Bidirectional dc-dc power stage modeling and control}

Some researchers developed a switch frequency-dependable average method to estimate the system performance at different switching frequencies. This is an extended statespace averaging model and is developed to predict large- and small-signal characteristics of the converter in either direction power flow. The model is especially designed for isolated one.

A digital controller was built after non-linear dynamic model of the converter was derived using a state space averaging method .Although it utilized the simplified power stage model with the traditional modeling approach, it did claim to handle seamless bidirectional operation. In fact, to design a seamless bidirectional power flow control, more generalized power stage model is needed. An analog current-injection-control in multiphase was implemented. One error

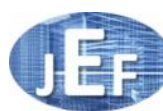


amplifier was used for the spacecraft bus voltage regulation with internal peak current mode control.

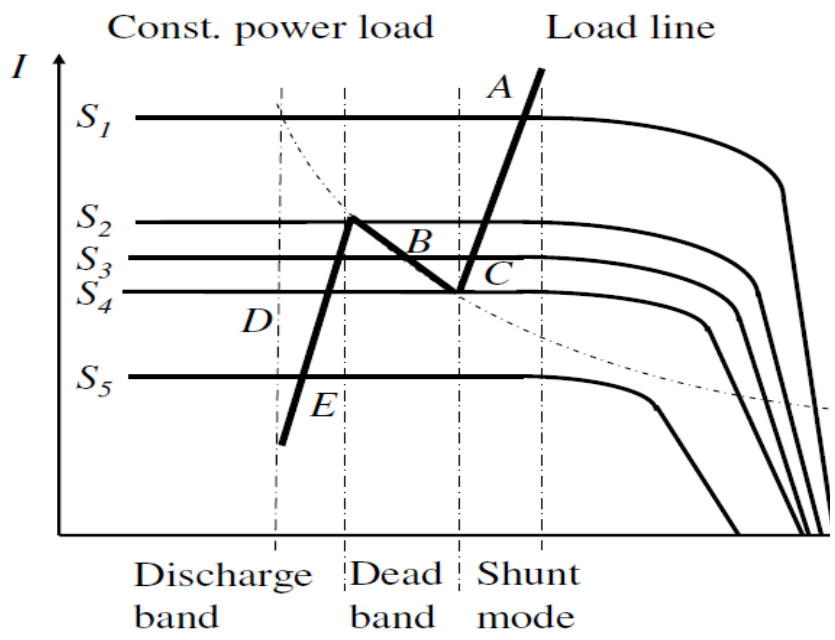

Fig. 1 Graphical analysis of sunlight to eclipse transition

After careful analysis of the feature of the two modes, a sub-optimal controller was proposed for the regulation of the two mode operations. It was expected to reduce the overall system weight. Since the application was focused on the spacecraft power system, no more average current control for both directions was addressed.

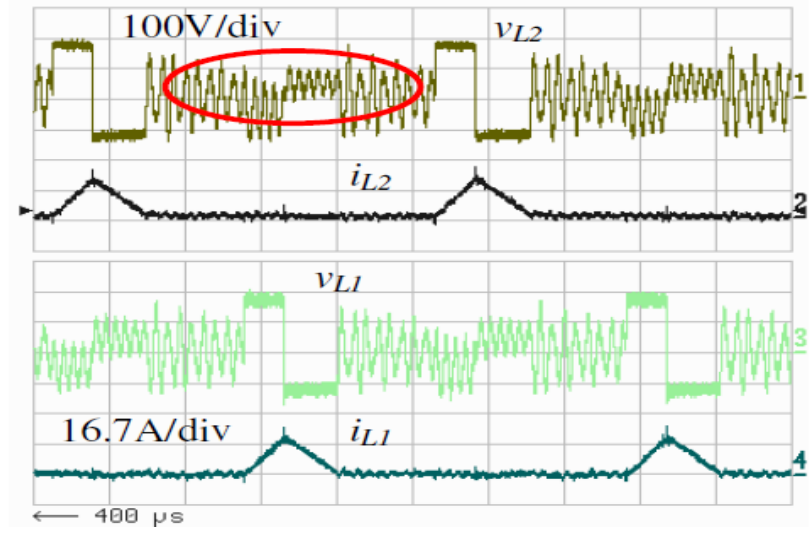

Fig. 2 Inductor voltage parasitic ringing at DCM operation
The non-isolated, multiphase bidirectional dc-dc power converter has been selected to achieve high power density in this dissertation. Usually, to increase the power density, the design adopts small inductor with multiphase to operate in discontinuous conduction mode. The problem with DCM operation as shown in Figure 2 is the related parasitic ringing caused by the inductor and the device output capacitance during current turn-off condition, resulting poor efficiency and significant EMI noises. The disadvantages related to the DCM are: a. Inductor voltage parasitic ringing,

b. Hard switching turn-off and increased turn-off loss.

The novel technique is to add a lossless snubber capacitor across each switch for soft turn-off and to use complementary gating signal control scheme to realize ZVRT (Zero Voltage Ride Through) for soft turn-on, thus achieving both soft turn-on and -off. This means after fully discharging the snubber capacitor energy the originally non-active switch diverts the current into the anti-paralleled diode of the active switch so that the main switch can turn on under zero voltage condition [5]-[6].

\section{Mode transitions related issues in bidirectional dc-dc converter}

The power flow smooth transition control of the bidirectional dc-dc converter is also quite challenged. Normally, three operating modes are required in inverter charger.

a) Wide range output voltage regulator for boost discharging mode

b) Wide range current regulation for buck charging mode

c) Wide range voltage regulation for absorb and float charging mode 


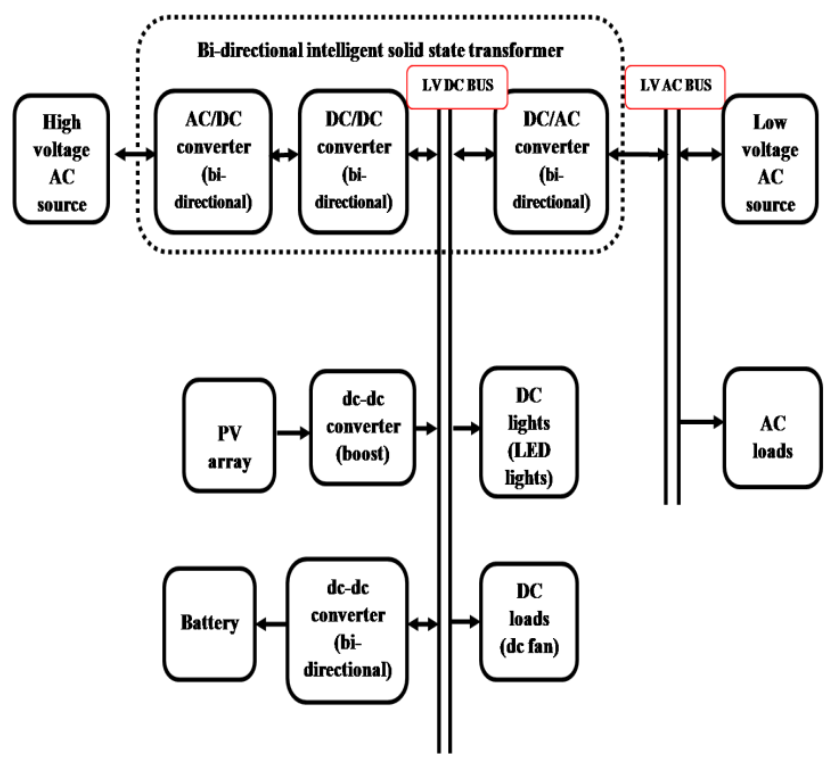

Fig. 3 Block diagram of SST microgrid
The distributed generation (DG) system consist of the AC grid which is a high voltage AC side and DC grid which is low voltage dc side, bidirectional AC-DC converter and (High Voltage Side Bi-Directional AC/DC Rectifier, Bidirectional DC-DC converter, Bidirectional Full bridged DC-AC converter)Those components are collectively called as BIST (bidirectional intelligent Semi-conductor transformer).in addition to that it has some renewable generation sources such as solar and hybrid energy storage systems. The BIST (bidirectional intelligent Semi-conductor transformer) performs the process of converting high voltage high power AC into a low voltage and nominal frequency $\mathrm{AC}$ through an Intelligent Solid-State Transformer. Battery energy storage system is used for power management depends upon demand response.

\section{Simulation description}

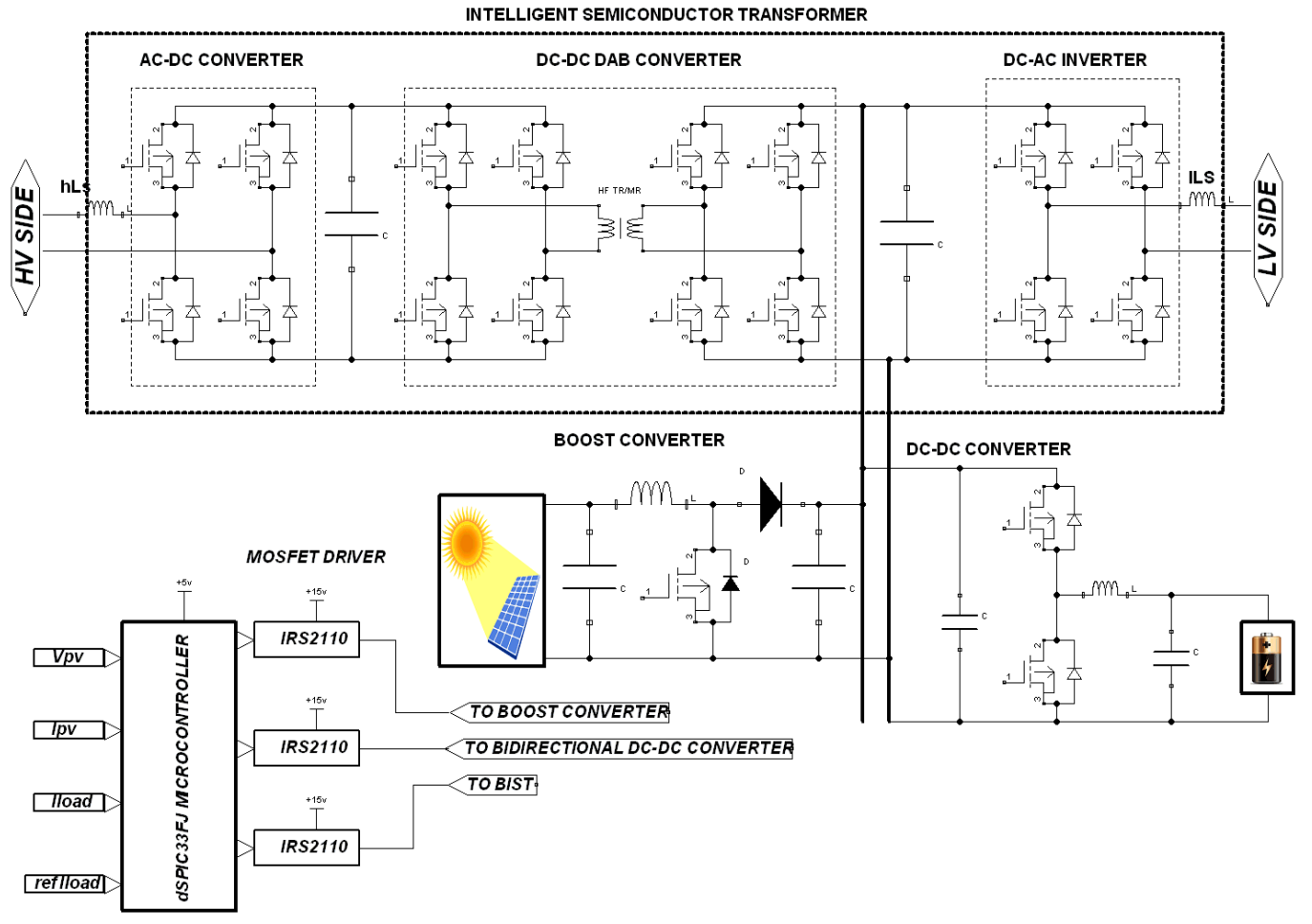

Fig. 4 Simulation diagram of bidirectional intelligent semiconductor transformer 
There are four modes of operation in SST

\section{Mode 1:}

During this mode the semiconductor transformer perform step down operation. When the power generation is not sufficient in solar, the demand in low voltage side is fulfilled by high voltage ac side. The battery also takes charging.

The charge from the voltage is supplied to load when the demand increases. So the operation starts from high voltage side to the low voltage side. The simulation output of SST and DC microgrid output have been shown to study the demand at particular time.

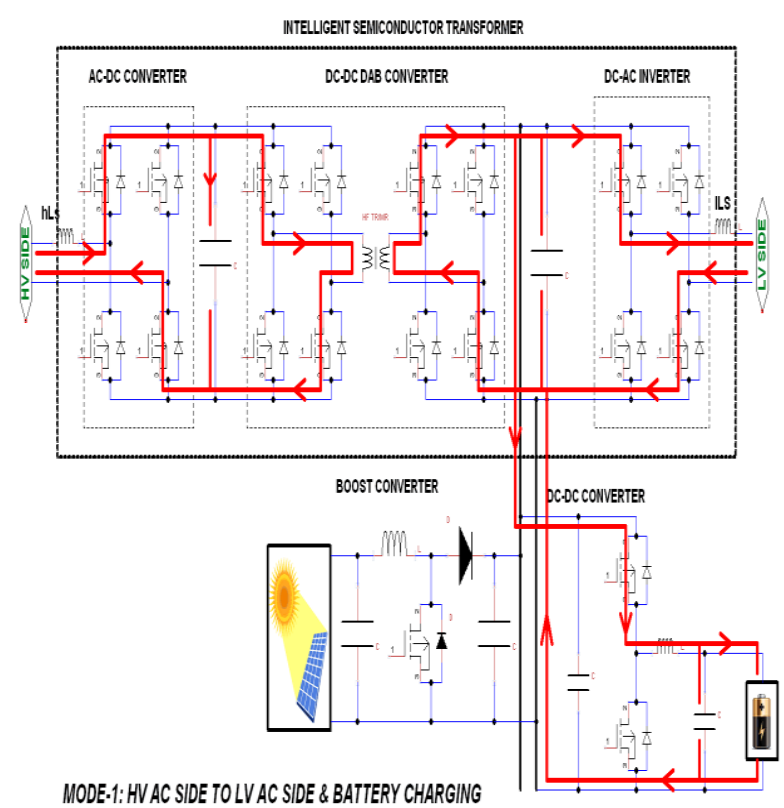

\section{Mode 2:}

During this mode we have sufficient generation at our solar plant. The load demand at LV side fulfilled by solar power and the mean time battery also charging.

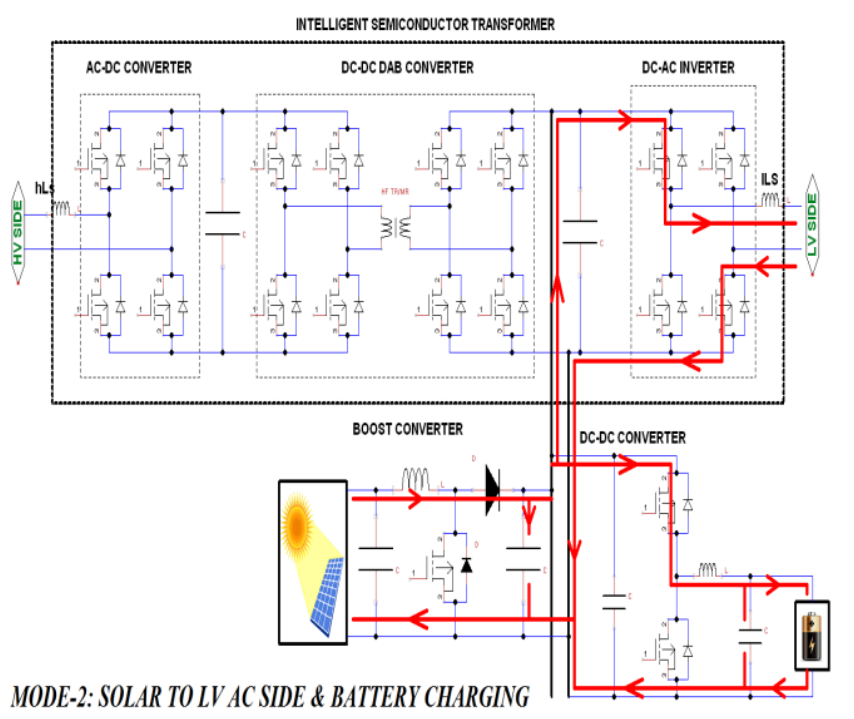




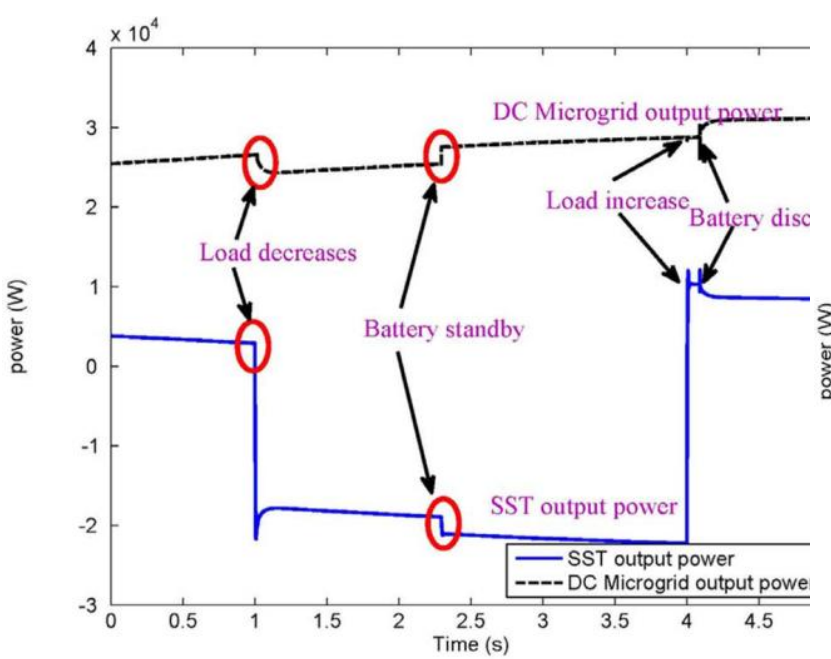

Fig. 6 Simulation results for mode 2, SST and DC microgrid output power.

\section{Mode 3:}

During this mode the power generation is not sufficient and soc of battery will be high. so the load demand by low voltage side fulfilled by solar and battery power.

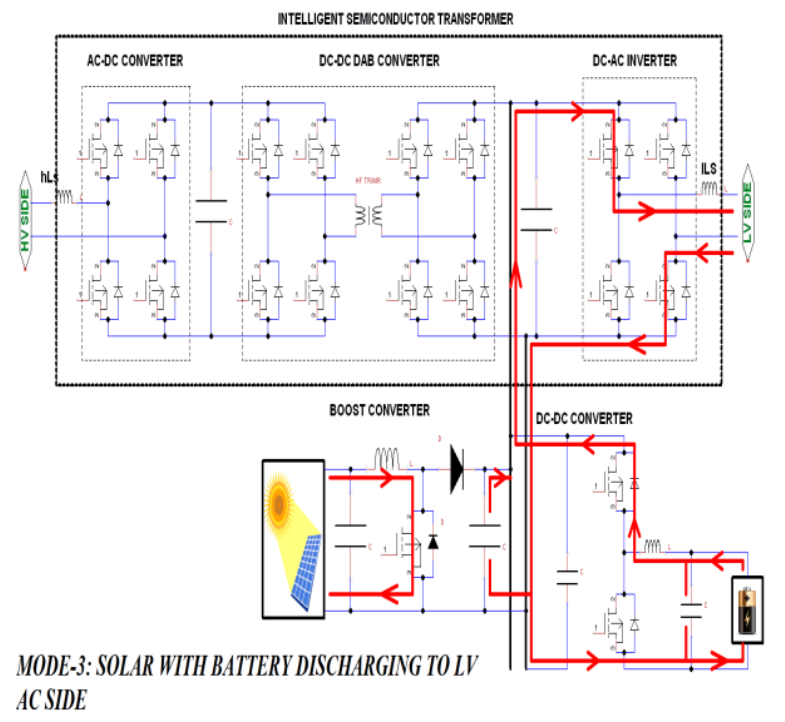

AODE-3: SOLE

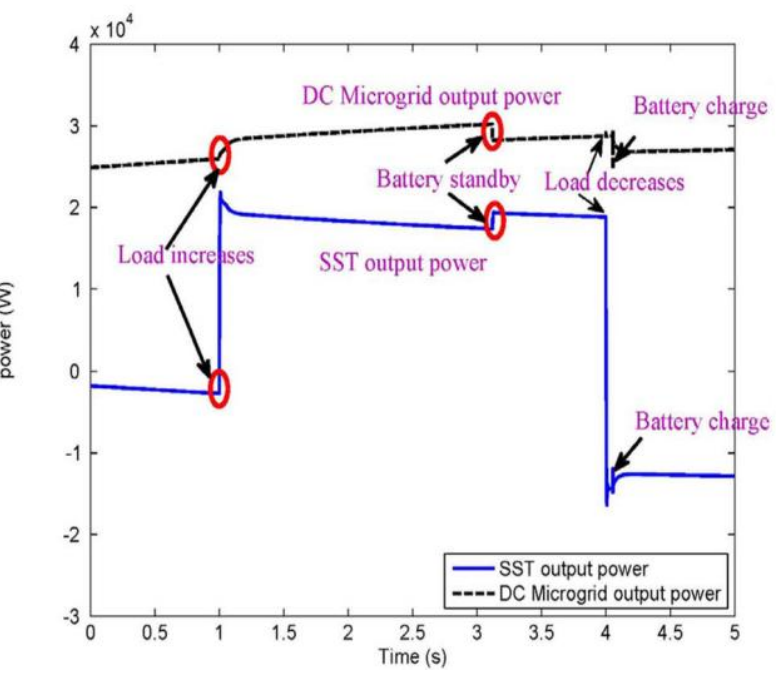

Fig. 7 Simulation results for mode 2, SST and DC microgrid output power.

\section{Mode 4:}

During this mode the load demand will be very low and having surplus power at dc microgrids. The excessive power transferred to high voltage conventional ac grid through semiconductor transformer. During this mode the SST act as step up transformer.

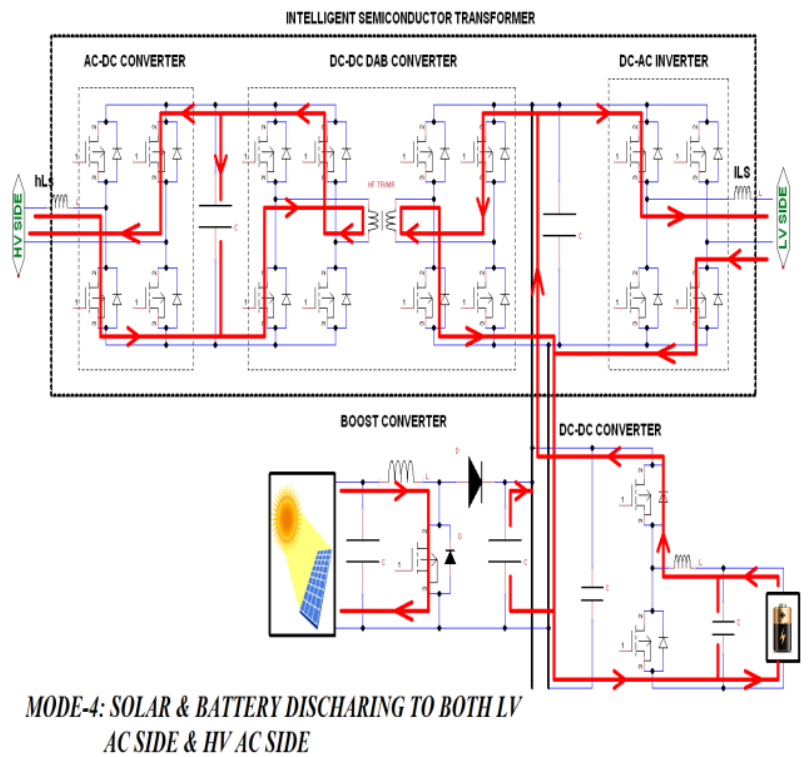

7. Simulation and hardware output and results

The simulated output of the bidirectional semiconductor transformer is shown in the below figure 


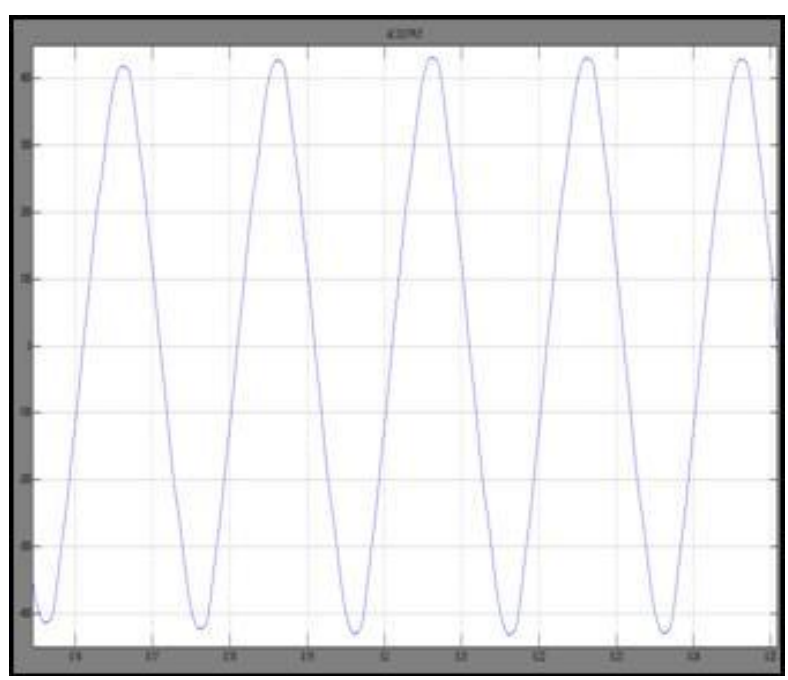

Fig. 8 Simulation Output waveform

Thus by giving variable voltage as the input and a maximum voltage capacity of $1900 \mathrm{kV}$ AC we get the constant 400V AC supply.

Also an built in model was developed to discuss the SST topology with minimal components and measurable values

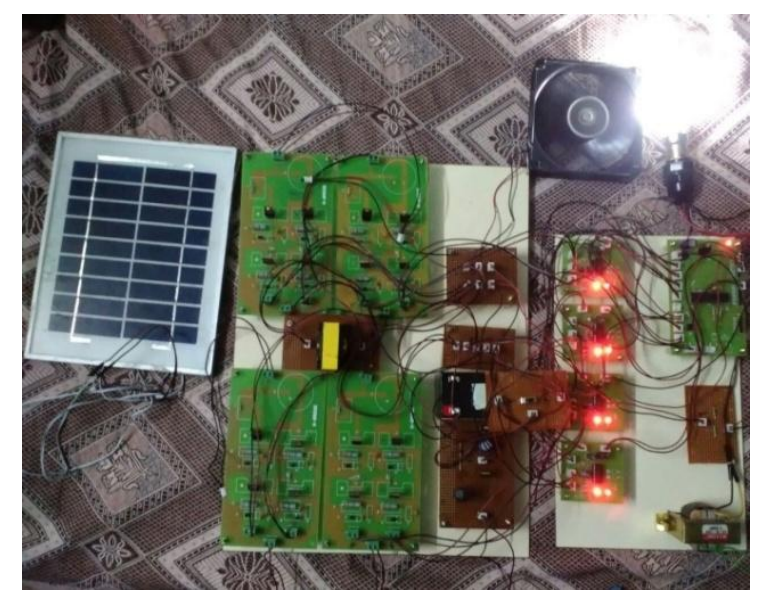

Fig. 9 Hardware kit of SST

\section{Conclusion}

A novel distributed power management strategy is proposed in this paper for SST with DC microgrid, which includes DRER (distributed renewable energy source) and DESD (distributed energy storage device). SST is adopted to interface the DC microgrid, AC load and the distribution system. The proposed distributed control algorithms for SST, fuel cell, PV and battery are also presented based on their different characteristics. In this power management strategy, the system can seamlessly switch between charging mode and discharging mode. In addition, since SOC of battery is considered into the power management, battery can intelligently switch its control algorithm based on its SOC and the system information without the communication involved. To verify the proposed topology, the corresponding simulation model is made as hardware and the results were verified practically.

\section{References}

[1] F. Katiraei and M. R. Irvine, "Power management strategies for a microgrid with multiple distributed generation units," IEEE Trans. Power Syst., vol21, no. 4, pp. 1821-1831, 2006.

[2] J. Schonberger, R. Duke, and S. D. Round, "DC-bus signaling: A distributed control strategy for a hybrid renewable nanogrid," IEEE Trans. Ind. Electron., vol. 53, no. 5, pp. 1453-1460, 2006.

[3] J.Wei and B. Fahimi, "Active current sharing and source management in fuel cell-battery hybrid power system," IEEE Trans. Ind. Electron.,vol. 57, no. 2, pp. 752-761, 2010.

[4] M. Arindam , S. Ashok, G. Mahesh, B. Simon and D. Shoubhik "Intelligent universal transformer design and applications", Proc. 20th Int. Conf. Exhib. Elect. Distrib., pp.1 -7 2009.

[5] M. N. Kheraluwala, R. W. Gascoigne, D.M.Divan,andD.Baumann, "Performanc e characterization of a high-power dual active bridge dc-to-dc converter," IEEE Trans. Ind. Electron., vol. 28, no. 6, pp. 1294-1301, 1992.

[6] R. H. Lasseter and P. Paigi, "Microgrid: A conceptual solution," in Proc. IEEE Power Electron. Spec. Conf. (PESC'04), Jun. 2004, vol. 6, pp. 4285-4290.

[7] S. Bhattacharya, T. F. Zhao, G. Y.Wang, S. Dutta, S. Baek, Y. Du, B.Parkhideh, X. H. Zhou, and A. Q. Huang, "Design and development of generation-I silicon based solid state transformer," in Proc. IEEE APEC, 2010, pp. 1666-1673. 
[8] Y. Xie, J. Sun, and J. S. Freudenberg, "Power flow characterization of a bidirectional galvanically isolated highpower dc/dc converter over a wide operating range," IEEE Trans. Power. Electron., vol. 25, no. 1, pp. 54-66, Dec. 2010.

[9] E. R. Ronan, S. D. Sudhoff, S. F. Glover, and D. L. Galloway, "A power electronic-based distribution transformer," IEEE Trans. Power. Del., vol. 17, no. 2, pp. 537-543, Apr. 2002.

[10] J. Bryan, R. Duke, and S. Round, "Decentralized generator scheduling in a nanogrid using dc bus signaling," in Proc. IEEE Power Eng. Society General Meeting, 2004, pp. 977-982. 